\title{
Delivering the right care to people with low back pain in low- and middle-income countries: the case of Nepal
}

\author{
Sweekriti Sharma ${ }^{1,2}$, Adrian C Traeger ${ }^{1,2}$, Shiva Raj Mishra ${ }^{3}$, Saurab Sharma ${ }^{4}$, \\ Chris G Maher ${ }^{1,2}$
}

\footnotetext{
${ }^{1}$ Sydney School of Public Health, Faculty of Medicine and Health, The University of Sydney, Sydney, Australia

${ }^{2}$ Institute for Musculoskeletal Health, Sydney, Australia

${ }^{3}$ Nepal Development Society, Bharatpur, Nepal

${ }^{4}$ Kathmandu University School of Medical Sciences, Dhulikhel, Nepal
}

Low back pain is the number one cause of disability in Nepal and the burden is increasing.

\begin{abstract}
A recent Lancet series [1] and World Health Organization commission [2] have highlighted the urgent need for all nations to increase attention on delivering appropriate, affordable care for non-communicable diseases (NCDs). One of the most critically under-prioritised NCDs in Nepal is low back pain.
\end{abstract}

Globally, 60.1 million disability-adjusted life-years were due to low back pain in 2015, which increased by 54\% since 1990 [3]. The most notable increase was in low- and middle-income countries. According to Global Burden of Disease data, low back pain is the number one cause of disability in Nepal; since 2005 the number of years lived with disability due to low back pain in Nepal increased by 16.9\% [4]. Nepal has a largely agrarian economy and one quarter of the population live below the poverty line. Inability to perform physically demanding work due to low back pain will drive many Nepali people into poverty. High health care cost alone could drive an additional 800000 people into poverty each year [5].

Nepal faces major challenges to reduce the burden of low back pain. There is an undersupply of health professionals with adequate training [6]. Nepal has less than one physiotherapist per 20000 people [7], most of whom work in urban areas (Australia has 24 physiotherapists per 20000 people). Moreover, the Lancet series [1] identified a worrying trend: health professionals in low- and middle-income countries providing the wrong care for low back pain. Over a three-month period in 2012, Nepali doctors ordered 722 MRIs to investigate the cause of low back pain [8]. MRIs have little clinical value for low back pain and would cost the average Nepali person approximately one third of their monthly household income. Although Nepal began piloting of insurance schemes as early as 1990s, they are yet to achieve tangible results. Furthermore, only $6.4 \%$ of the total government health spending was allocated to NCDs in 2014 [6].

Resource-poor settings such as Nepal have a tremendous task ahead of them. It is unrealistic to expect governments to shift spending away from urgent issues such as maternal health (only $58 \%$ of deliveries in Nepal had skilled birth attendants present) to 
Nepal faces major challenges to reducing the burden of low back pain including an undersupply of health professionals, overuse of ineffective healthcare services, and high out-of-pocket expenses. non-life-threatening conditions such as low back pain. Given the profound socioeconomic burden of low back pain, a wise place to start would be to integrate care for low back pain with existing services. South Africa recently integrated back pain information into a national NCD project which spanned community, work and school settings [9]. Community-led programs for peer-education targeting physical activity [10] could also be a useful entry point for integrating information about low back pain. This approach would accord with the World Health Organization's 'best buy' interventions - cost-effective interventions to improve health for $\leq \mathrm{I} \$$ 100 per DALY averted. These strategies should be accompanied by increased investment in affordable, evidence-based services for low back pain.

The Nepal NCD and Injury Poverty Commission listed 25 priority NCDs and injuries. Low back pain was not one of them [6]. With 2018 being the year to address NCDs [2], we believe now is the time to prioritise low back pain in Nepal and other low- and middle-income countries.

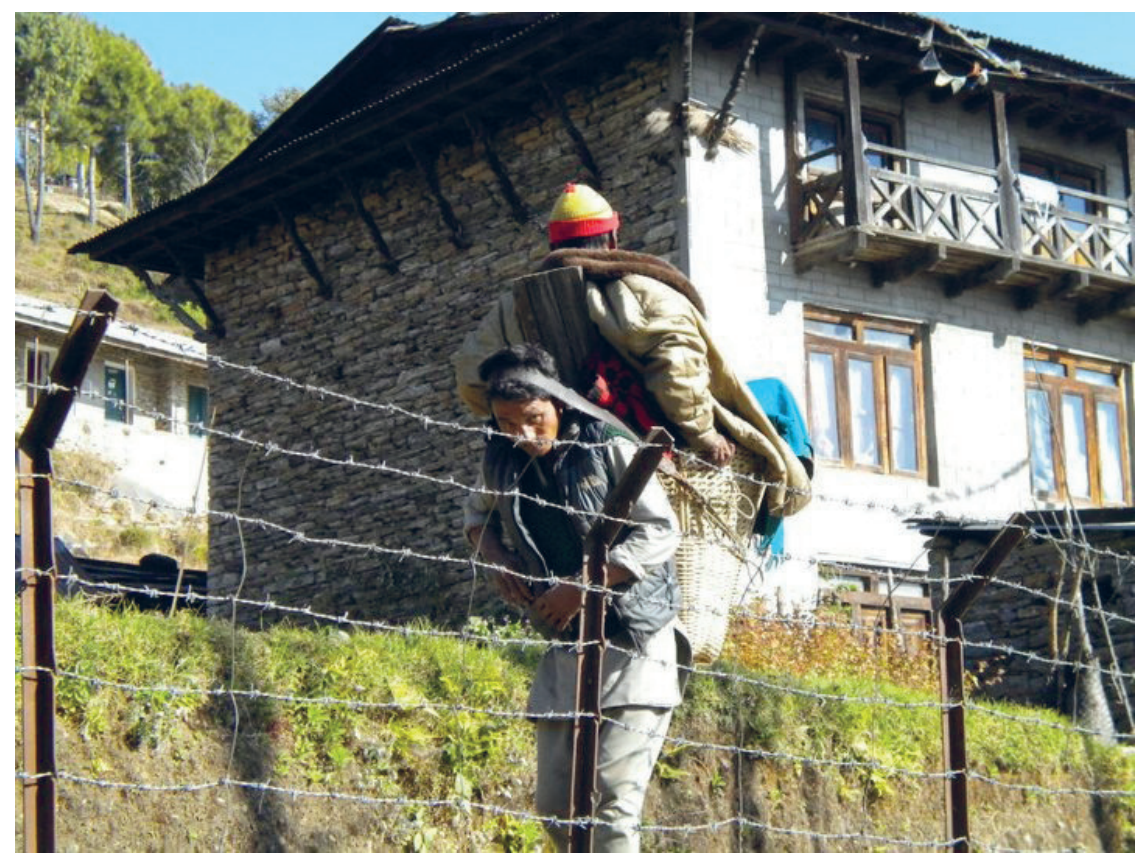

Photo: Patient being transported to the local health post (from the collection of Saurab Sharma, used with permission)

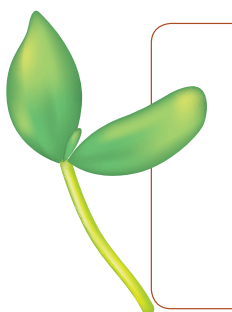

Funding: None.

Author's contribution: AT, CM and SwS conceived the idea. SwS developed the first draft. SwS, AT, SM, SaS and CM contributed intellectual content to subsequent drafts and approved the final version.

Competing interests: The authors have completed the Unified Competing Interest form at www.icmje.org/coi_ disclosure.pdf (available on request from the corresponding author) and declare no conflict of interest.

1 Hartvigsen J, Hancock MJ, Kongsted A, Louw Q, Ferreira ML, Genevay S, et al; The Lancet Low Back Pain Series Working Group. Low back pain. Lancet. 2018;391:2356-67. Medline:29573870 doi:10.1016/S0140-6736(18)30480-X

2 Nishtar S, Niinistö S, Sirisena M, Vázquez T, Skvortsova V, Rubinstein A, et al. Time to deliver: report of the WHO Independent High-Level Commission on NCDs. Lancet. 2018;392:245-52. Medline:29866374 doi:10.1016/S01406736(18)31258-3

3 GBD 2015 Disease and Injury Incidence and Prevalence Collaborators. Global, regional, and national incidence, prevalence, and years lived with disability for 310 diseases and injuries, 1990-2015: a systematic analysis for the Global Burden of Disease Study 2015. Lancet. 2016;388:1545-602. Medline:27733282 doi:10.1016/S0140-6736(16)31678-6 
4 Institute for Health Metrics and Evaluation. What health problems cause the most disability? 2018. Available: http:// www.healthdata.org/nepal. Accessed: 14 June 2018.

5 Adhikari SR. Universal Health Coverage Assessment Nepal. Ottawa, Canada: Global Network for Health Equity; 2015.

6 The Lancet. The Nepal NCDI Poverty Commission: National Report. 2018. Available: http://www.ncdipoverty.org/nepal-report/. Accessed: 14 June 2018.

7 Sharma S. Physiotherapy Regulation in Nepal. International Network of Physiotherapy Regulatory Authorities. 2017. Available: https://www.slideshare.net/saurabsharma/physiotherapy-regulation-in-nepal. Accessed: 26 June 2018.

8 Dahal S, Joshi A, Pant S. Spectrum of Lumbar Spine Pathologies in Patients with Low Back Pain on MR Examination: A Retrospective Hospital Based Study. Post-Graduate Medical Journal of NAMS. 2015;12:36-40.

9 South African Western Cape Government. Wow! (Western Cape on Wellness) Healthy Lifestyle Initiative. 2017. Available: https://www.westerncape.gov.za/westerncape-on-wellness/about-us. Accessed: 27 June 2018.

10 Vaidya A, Oli N, Eiben G, Krettek A. The Heart-health Associated Research, Dissemination and Intervention in the Community (HARDIC) Trial for Nepalese Mothers regarding diet and physical activity: A process evaluation. Kathmandu Univ Med J. 2017;58:107-16.

\section{Correspondence to:}

Sweekriti Sharma

The University of Sydney

Level 10 North, King George V Building

Royal Prince Alfred Hospital (C39)

PO Box M179, Missenden Road, NSW, 2050, Australia Sweekriti.sharma@sydney.edu.au 